\title{
Methamphetamine reinforcement in rats
}

ROY PICKENS AND RICHARD MEISCH, UNIVERSITY OF MINNESOTA LOUIS E. MCGUIRE, ${ }^{2}$ UNIVERSITY OF MISSISSIPPI

Methamphetamine was found to serve as a reinforcer for the rat. Long-term drug self-administration was characterized by periods of responding and not responding for drug injection. Response rate varied as a function of drug dosage and value of a fixed-ratio reinforcement schedule.

Studies investigating the variables which influence drug reinforcement have been concerned primarily with the self-administration of morphine by physicallydependent animals (Thompson \& Schuster, 1964; Weeks \& Collins, 1964). Until recently little attention has been given drugs which are self-administered but do not produce physical dependence. One of these, methamphetamine, has been reported to be self-administered by both monkeys and humans (Edwards, 1965; Deneau, personal communication). The present study demonstrated that methamphetamine self-administration is a drug-reinforcement effect in the rat and determined the effects of drug dosage and infusion contingencies on this behavior.

\section{Subjects}

The Ss were Holtzman male albino rats, approximately 150 days old. The apparatus was three operant conditioning chambers, one containing a metal band and two containing single levers as the response key. The technique for drug self-administration(Davis, 1966) involved preparing each $\mathrm{S}$ with a chronically indwelling jugular catheter that connected via tubing to a remote infusion pump. By closing the response key, the $S$ activated the infusion pump and received an intravenous injection of a fixed volume of drug solution. The frequency and distribution of responses for drug infusion were recorded and constituted the primary data for the study.

\section{Experiment 1}

The first experiment was designed to determine whether methamphetamine serves as a reinforcer for the rat. One characteristic of reinforcers is to increase the frequency of occurrence of the response they follow (Skinner, 1966). Therefore, 16 Ss were divided into eight experimental/control pairs and given a single 90-min training session. For the experimental $\mathrm{Ss}$, band-touching responses produced a $1.5-\mathrm{sec}$ infusion of $0.25 \mathrm{mg} / \mathrm{kg}$ methamphetamine hydrochloride in isotonic saline solution. For the control Ss, responding had no programmed consequence. However, these animals received the same number and temporal distribution of methamphetamine infusions as their experimental partner, in order to control for increases in response rate due to drug effects other than reinforcement (e.g., increased general activity). The mean number of responses during train- ing was 49.88 for experimental Ss and 23.25 for controls. The difference was statistically significant $(t=2.37, p<.025)$ and indicated that methamphetamine was a reinforcer for the rat.

\section{Experiment 2}

In a second experiment, three $S$ s were allowed to respond for methamphetamine reinforcement $24 \mathrm{~h}$ per day for a period of several weeks. Each lever press by the $S$ was followed by a 50-sec infusion of 0.5 $\mathrm{mg} / \mathrm{kg}$ of drug, with a small cage light illuminated during infusion. During the first one to two days of the experiment, rate of responding for drug injection was low and erratic. On about the third day response rate began to increase and by the fourth or fifth day had stabilized with a fairly constant interval separating each infusion. For the remainder of the experiment, discrete periods of regularly-spaced responding alternated with periods of no responding. The periods of drug responding lasted from 24-48 h and terminated abruptly without intermediate response rates or other changes commonly seen during extinction or satiation. Periods of drug abstinence usually lasted from 12-24 $\mathrm{h}$, during which time the animals typically slept and ate. Drug responding was initiated again either voluntarily by the animal or, following an abstinence period of several hours, by the delivery of a forced drug injection. Onset of responding was abrupt, with immediate spacing of responses. After approximately four weeks of drug self-administration, response patterning became irregular and subsequently deteriorated until it could not be detected.

Within the period of patterned methamphetamine self-administration, the amount of drug per infusion was varied to determine the effects of dosage on self-administration. Dosage values, varied separately

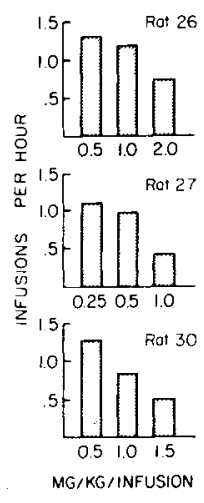

PATTERNS OF METHAMPHETAMINE INFUSIONS
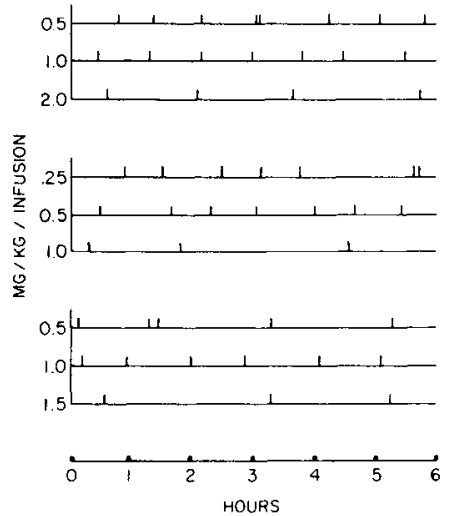

Fig. 1. Effects of drug dosage on the frequency and patteming of methamphetamine self-administrations. 
Table 1. Effects of fixed-ratio reinforcement on frequency and number of methamphetamine self-administrations.

\begin{tabular}{ccccc} 
Rat & Dosage mg/kg & FR Value & Responses per hr $\operatorname{lnfusions~per~hr~}$ \\
\hline 26 & 2.0 & 1 & .58 & .58 \\
& & 5 & 3.00 & .60 \\
& & 10 & 8.90 & .89 \\
27 & 0.5 & 1 & 2.12 & 2.12 \\
& & 3 & 3.78 & 1.26 \\
& & 5 & 8.10 & .1 .62 \\
30 & 1.0 & 1 & .85 & .85 \\
& & 3 & 2.01 & .67 \\
& & 5 & 5.00 & 1.00 \\
\hline
\end{tabular}

for each animal, ranged from 0.25 to $2.0 \mathrm{mg} / \mathrm{kg} /$ infusion, with behavioral recordings of at least $24 \mathrm{~h}$ for each value.

Figure 1 shows the effects of drug dosage on the frequency and patterning of responding for methamphetamine self-administration. The data presented are for periods of drug intake only. As can be seen, frequency of responding increased with decreases in drug dosage and decreased with increases in dosage, indicating that an inverse relationship exists between methamphetamine dosage and frequency of self-administration. The mean drug intake for the separate animals was $0.75,0.41$, and $1.18 \mathrm{mg} / \mathrm{kg} / \mathrm{h}$ for Rats 26,27 , and 30 , respectively. The mean drug intake for all animals over all dosages was $0.78 \mathrm{mg} / \mathrm{kg} / \mathrm{h}$. For each animal patterning of responding was more regular with the high dosage than with the low. The intermediate dosage appeared to produce the most regular responding.

Following determination of dosage effects, the Ss were placed on fixed-ratio (FR) reinforcement schedules for $0.5,1.0$, or $2.0 \mathrm{mg} / \mathrm{kg}$ methamphetamine. Fixed-ratio values ranged from one response per reinforcement (FR 1) to 10 responses per reinforcement (FR 10), and at least $24 \mathrm{~h}$ of data were collected with each value. Table 1 summarizes the results. When the value of a fixed-ratio schedule was increased, response frequency increased accordingly, and the number of drug reinforcements per hour remained essentially the same. A comparison of drug intake by all animals for FR 1 and FR 5 reinforcement indicated that about the same amount of drug was taken under each schedule $(1.02$ and $1.00 \mathrm{mg} / \mathrm{kg} / \mathrm{h}$, respectively, for FR 1 and FR 5). The mean drug intake for all animals over all ratio values was 1.01 $\mathrm{mg} / \mathrm{kg} / \mathrm{h}$.

Discussion

The finding with methamphetamine that responding for drug reinforcement varies inversely as a function of drug dosage and directly as a function of value of a fixed-ratio reinforcement schedule has also been reported with morphine (Weeks \& Collins, 1964). One essential difference in the self-administration of morphine and methamphetamine appears to be that morphine responding continues uninterrupted over a relatively long period of time, whereas methamphetamine responding is characterized by alternating periods of drug intake and abstinence. This difference may be related to the fact that morphine deprivation produces aversive withdrawal symptoms, while methamphetamine deprivation does not.

\section{References}

Davis, J. D. A method for chronic intravenous infusion in freely moving rats. J. exp. Anal. Behav., 1966, 9, 385-387.

Edwards, R. E. Abuse of central nervous sy stem stimulants. Amer. J. Hosp. Pharm., 1965, 22, 144-147.

Skinner, B. F. Operant behavior. In W. H. Honig (Ed.), Operant behavior: Areas of research and application. New York: Appleton-Century-Crofts, Inc., 1966.

Thompson, T., \& Schuster, C. R. Morphine self-administration, food-reinforced and avoidance behaviors in rhesus monkeys. Psychopharmacologia, 1964, 5, 87-94.

Weeks, J. R., \& Collins, R. J. Factors affecting voluntary morphine intake in self-maintained addicted rats. Psychopharmacologia, 1964, 6, 267-279.

\section{Notes}

1. Preparation of the article was supported in part by training grant MH-08565 and research grant MH-11135 to the University of Minnesota.

2. A portion of this article was based on a thesis submitted by L. E. McGuire in partial fulfillment of the requirements for the Ph.D. degree at the University of Mississippi. 